\title{
DLC Films Deposited by the DC PACVD Method
}

\author{
D. Palamarchuk, M. Zoriy, J. Gurovič, F.Černý, S. Konvičková, I. Hüttel
}

DLC (Diamond-Like Carbon) coatings have been suggested as protective surface layers against wear. However hard DLC coatings, especially those of greater thickness, have poor adhesion to substrates. We have used several ways to increase the adhesion of DLC coatings prepared by the PACVD (Plasma Assisted Chemical Vapour Deposition) method on steel substrates. One of these is the DC PACVD method for preparing $D L C$ films.

Keywords: DLC, PACVD, microhardness, adhesion.

\section{Introduction}

Diamond-like carbon (DLC) films have attracted considerable attention recently due to their properties of high mechanical hardness, high electrical resistivity, low friction coefficient, optical transparency and chemical inertness [1]. These properties make DLC films suitable for numerous potential applications in hard and wear-resistant coatings, lithography, protective optical and biomechanical coatings, electroluminescence materials and field-emission devices [2, 3]. Various techniques have been used for preparing DLC film, including ion-beam deposition, reactive magnetron sputtering, pulsed laser deposition, a filtered cathodic vacuum arc, direct current plasma CVD, radio frequency plasma CVD and electron cyclotron resonance microwave plasma CVD [4-7].

A problem that affects some of these methods is their poor adhesion to steel substrates with no intermediate layer. One potential solution to this problem is to use current plasma for depositing DLC films with no intermediate layer. This paper studies the adhesion of DLC films to steel substrates and the microhardness of the layer.

\section{Experimental and results}

The DLC films were deposited with a direct current plasma assisted chemical vapor deposition process (DC PACVD) on silicon (111) and steel substrates. The steel substrate consists of $0.9 \% \mathrm{C}, 4.14 \% \mathrm{Cr}, 6.1 \% \mathrm{~W}, 5 \% \mathrm{Mo}$, $2.02 \% \mathrm{~V}$. These samples were polished up to a mirror finish, using a series of standard metallurgical polished steps.

Before preparation, the samples were cleaned with acetone and isopropanollian in an ultrasonic bath.

The apparatus for plasma assisted chemical vapor deposition consists of a vacuum chamber, a diffusion pump, two parallel electrodes and a generator of DC PACVD plasma. A part of the PACVD apparatus is illustrated in Fig.1.

The DLC films were prepared on our substrates with the same parameters, apart from the bias voltage, which was varied. This parameter was varied between $-400 \mathrm{~V}$ and $-900 \mathrm{~V}$. Other processing parameters of the DLC layers, prepared with different values of the bias voltage, are shown in Table 1.

The thickness of the deposited DLC films was approximately $1 \mu \mathrm{m}$, with different values of bias voltage.

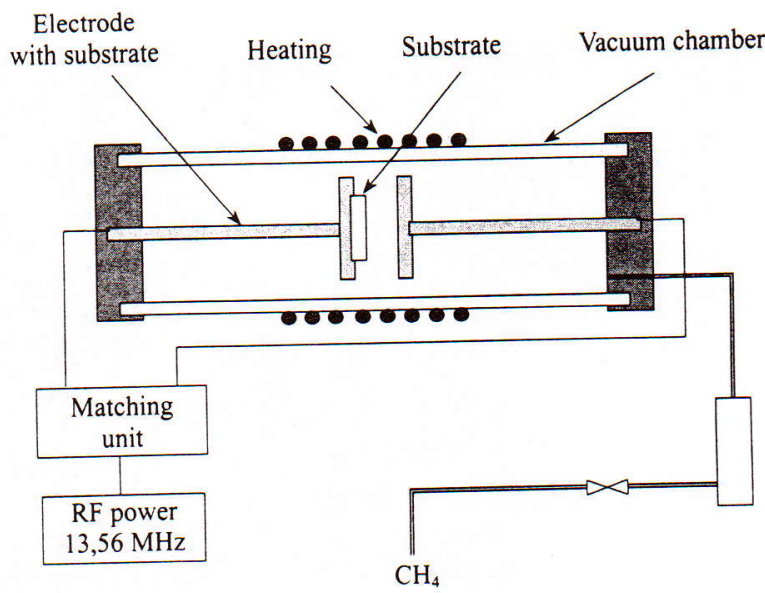

Fig. 1: Schematic view of DC PACVD apparatus

Table 1: Deposition parameters of DLC films

\begin{tabular}{|c|c|c|c|}
\hline & Parameter & Silicon substrate & Steel substrate \\
\hline 1. & Initial vacuum & $3.9 \cdot 10^{-2}$ Torr & $3.9 \cdot 10^{-2}$ Torr \\
\hline 2. & Pressure of $\mathrm{CH}_{4}$ & $7.1 \cdot 10^{-1}$ Torr & $7.1 \cdot 10^{-1}$ Torr \\
\hline 3. & Bias current & $60 \mathrm{~mA}$ & $60 \mathrm{~mA}$ \\
\hline 4. & Bias voltage & $-400 \mathrm{~V} \div-900 \mathrm{~V}$ & $-400 \mathrm{~V} \div-900 \mathrm{~V}$ \\
\hline 5. & $\begin{array}{c}\text { Thickness of } \\
\text { DLC layer }\end{array}$ & $\approx 1 \mu \mathrm{m}$ & $\approx 1 \mu \mathrm{m}$ \\
\hline
\end{tabular}

Then we investigated the dependence of microhardness on bias voltage and the adhesion of the DLC layers to the steel substrate.

The microhardness of the substrates and substrates with DLC films was measured using a Leica DM Inverter Research Microscope for Materials Testing. The measurement results of microhardness for DLC layers prepared with the different values of bias voltage are shown in Fig. 2.

These graphs show the microhardness of the DLC layers, which increases with increasing bias voltage.

The photographs of the Vickers indentations clearly demonstrate the difference between layers with good and poor adhesion. The indentation in layers with poor adhesion to the substrate exhibits cracks in the diagonal direction. In the case of good adhesion no cracks are visible, and the layer remains compact. This difference is shown in Fig. 3. 

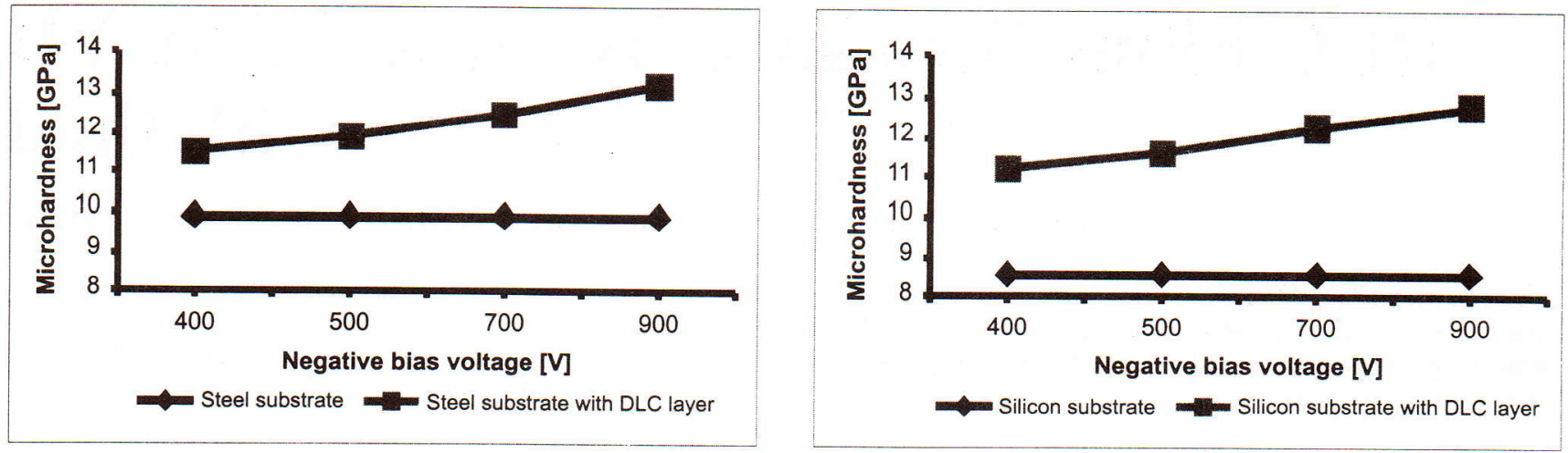

Fig. 2: Dependence of microhardness on bias voltage of DLC layers on silicon and steel substrates
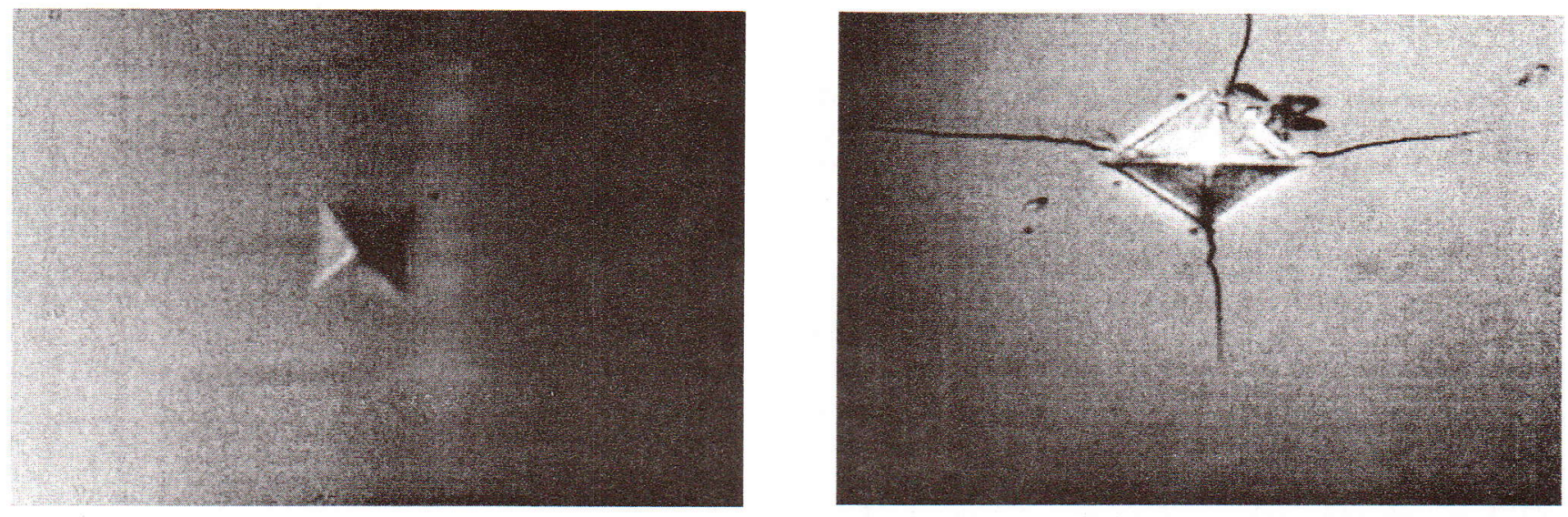

Fig. 3: Shape of Vickers indentation in layers with good and poor adhesion

The microhardness of the coated materials is about $13 \mathrm{GPa}$ higher than the base material at a load of $50 \mathrm{mN}$ and bias voltage $-900 \mathrm{~V}$.

These coatings can be used for example for protecting metal bioimplants [8].

\section{Acknowledgment}

This work was supported by a grant from the Grant Agency of the Czech Republic 106/02/1194 , J04/98:210000012 and CTU0204112.

\section{References}

[1] Robertson, J.: Adv. Physics, Vol. 35, 1986, p. 317.

[2] Lettington, A. H., Smith, C.: Diamond Relat. Mater., Vol. 1, 1992.

[3] Seth, J., Babu, S. V., Ralchenko, V. G.: Thin Solid Films, Vol. 254, 1995, p. 92.

[4] Nagai, I., Ishitani, A., Kuroda, H.: Journal Appl. Phys., Vol. 67, 1990, p. 2890.

[5] Harry, M., Zukotynski, S.: Journal Vac. Sci. Technol., A9, 1991, p. 496.

[6] Ganapathi, L., Giles, S., Rao, R.: Appl. Phys. Lett., Vol. 63, 1993, p. 993.

[7] McKenzie, D. R., Müller, D., Pailthorpe, B. A.: Phys. Rev. Lett., Vol. 67, 1991, p. 773.

[8] Konvickova, S., Valerian, D.: Acta Mechanica Slovaca, Vol. 2, 1989, p. 39 .
Ing. Dmytro Palamarchuk

e-mail: palamarc@student.fsid.cvut.cz

Ing. Miroslav Zoriy

Ing. Ján Gurovič

phone: +420224355600

e-mail: gurovic@fsid.cvut.cz

Doc. Ing. František Černý, CSc.

phone: +420224352437

e-mail: cernyf@fsid.cvut.cz

Department of Physics

Doc. Ing. S. Konvičková, CSc.

phone: +420224352511

e-mail: konvicko@fsid.cvut.cz

Department of Mechanics

Czech Technical University in Prague

Faculty of Mechanical Engineering

Technická 4

16607 Prague 6, Czech Republic

Doc. Ing. Ivan Hüttel, CSc.

phone: +420224353205

e-mail: huttel@vscht.cz

Institute of Chemical Technology

Technická 3

16628 Prague 6, Czech Republic 